\title{
Shoulderless Friction Stir Welding: a low-force solid state keyhole joining technique for deep welding of labile structures
}

\author{
Max Hossfeld ${ }^{1}$ (D
}

Received: 3 August 2021 / Accepted: 28 September 2021 / Published online: 8 October 2021

(c) The Author(s) 2021

\begin{abstract}
This paper reports on the possibility of performing Friction Stir Welding (FSW) without the usual immanent shoulder to enable FS processing to deep welding of narrow and labile structures and applications where backing is not possible. Requirements and prerequisites, advantages and limitations for Shoulderless Friction Stir Welding (SLFSW) are discussed and an industrial application of the joining technology is presented. For leaving the shoulder out, its central functions in FSW have to be transferred to the pin. The resulting tool design of SLFSW is comparably small and slim and so reduces contact area and effective lever and in turn forces and heat input during processing. SLFSW allows welding paths almost at the edge of components and enables a complete and gap-free joining while a deformation of overhanging structures can be avoided. Compared to standard FSW processes, force reductions of about $80-85 \%$ and power reductions of about $75-80 \%$ were found in this study for a $6.5 \mathrm{~mm}$ deep weld opening up additional potential for integration with other spindle processes like milling. The locally very limited process impact of SLFSW resulted in comparably low distortion with a part precision reached of $+/-0.05 \mathrm{~mm}$.
\end{abstract}

Keywords Friction Stir Welding · Shoulderless Friction Stir Welding · Tool design · shoulderless · Low distortion · Force reduction

\section{Introduction}

Friction Stir Welding (FSW) [18] as a solid-state joining process is mostly used today for the joining of aluminum alloys. Main features of FSW with respect to this research are the capability of reliably producing void free, vacuum tight joints with high static and cyclic joint efficiencies and a comparable low environmental impact $[6,12,16]$. The comparable low heat input and the absence of fumes, smoke, splatter etc. make FSW a relatively safe and clean welding process while in addition the similarity with milling enables great potentials for process integration. An overview of the standard FSW process, its parameters, microstructural zones, and the terminology used in this paper is shown in Fig. 1.

Main challenges for implementing FSW are the high process forces that result from FSW's solely mechanical established working principle [7]. Especially when producing

Max Hossfeld

max.hossfeld@ifsw.uni-stuttgart.de

1 InnovationCampus Future Mobility, University of Stuttgart, Stuttgart 70569, Germany deeper welds, process forces increase rapidly because of geometrical boundary conditions. Typical tooling concepts in FSW today use pin diameter to welding depth ratios of about 1 and shoulder to pin diameter ratios between 2.5:1 and $4: 1, \mathrm{cmp}$. [9, 12]. This circumstance results directly in a theoretical quadratic increase of the contact area with increasing welding depth and thus of normal and traverse forces but also spindle torque. For example, for butt joints on AA 5083 [5] about $5 \mathrm{kN}$ are required for a comparable fast weld in $3 \mathrm{~mm}$ and $20 \mathrm{kN}$ for $7 \mathrm{~mm}$ while welding $20 \mathrm{~mm}$ deep in the same material already requires $42 \mathrm{kN}$. With increasing shoulder diameter, contact area and effective lever, torque requirements rise quickly: $15 \mathrm{Nm}$ for the weld with $3 \mathrm{~mm}, 100 \mathrm{Nm}$ for $7 \mathrm{~mm}$ and even $280 \mathrm{Nm}$ for $20 \mathrm{~mm}$. With rising welding depth and process forces the overall heat input rises of course as well. But as the shoulder diameter increases, more and more material volume is processed more distant to the joint line. Since this is not actually needed for joining, the process efficiency deteriorates what can be recognized comparing the heat input per unit length of the welds: While $160 \mathrm{~J} / \mathrm{mm}$ are needed for the $3 \mathrm{~mm}$ deep weld, the $20 \mathrm{~mm}$ weld-around 6.5 times deeper-needs $2950 \mathrm{~J} /$ 
Fig. 1 Overview of microstructural zones, parameters and terminology of Friction Stir Welding

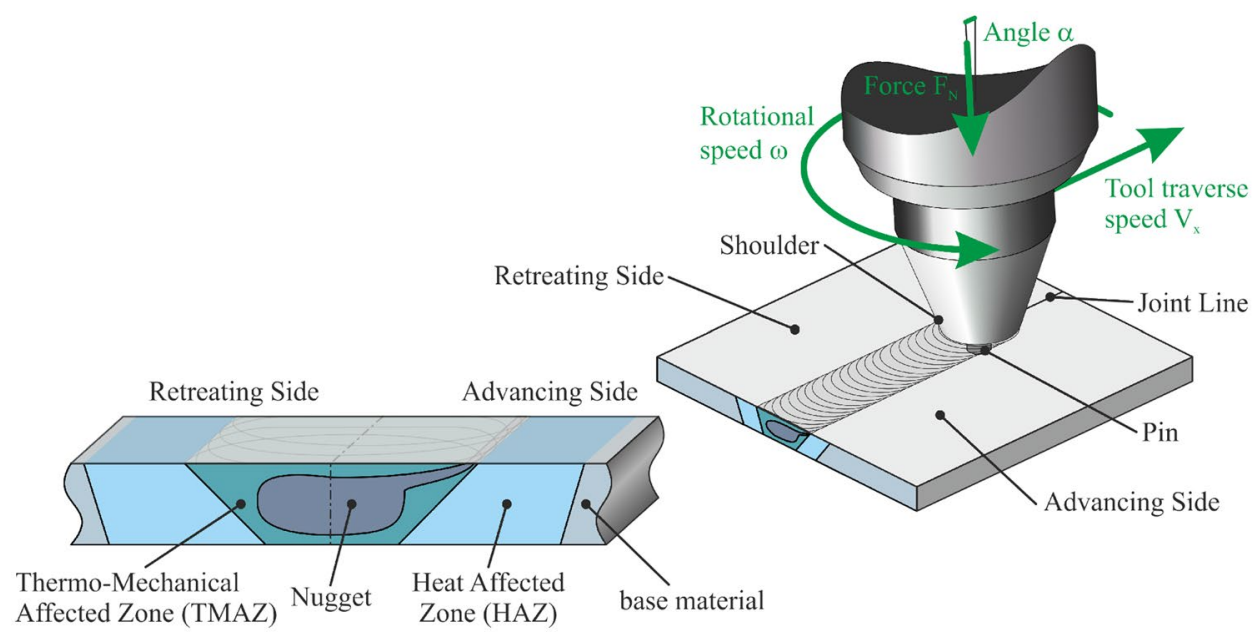

$\mathrm{mm}$, which is about 18.5 times as much. Furthermore, the higher and more spread heat input causes larger areas of the component to heat up and thus soften leading to a reduction in the inherent stability of the welded components.

Further force and pressure related issues especially arise when welding labile or overhanging structures. Since an actual joining in FSW is only possible where an intermixing of the softened material can mechanically be induced by the tool or the application of forces and torque respectively, parts have to be supported sufficiently from below and the side to support and to withstand those forces. Otherwise, the resulting material loss from the joining zone destabilizes the material flow which typically leads to welding defects, $\mathrm{cmp}$. [1], usually a void formation as shown in Fig. 2 (left).

A related issue to this is the full joining of parts up to a component's edge. Standard FSW processes are not able to join parts fully up to edges since the approach of a standard tool is limited to the point where its shoulder reaches the component's edge. By this no material flow or intermixing can be induced close to edges. As a consequence, the projected distance between shoulder and pin - often about one third of the shoulder diameter-remains unjoined, Fig. 2 (right).

Different approaches exist to address those issues in FSW. The most obvious and usual approach for force reduction is to adjust FSW's process parameters. As showed by Reza-E-Rabby et al. [13] for $12.7 \mathrm{~mm}$ deep welds on AA 6061-T651 an increased spindle speed from 160 to 200 $\mathrm{rpm}$ and therefore higher heat input per unit length leads to an increased probe temperature by about $25 \mathrm{~K}$ and reduced the average traverse force by about $40 \%$. Russell et al. [14] increased the spindle speed stepwise from 600 to $900 \mathrm{rpm}$ during welding $25 \mathrm{~mm}$ AA $6060-\mathrm{T} 6$ at $50 \mathrm{~mm} / \mathrm{min}$ welding speed. Starting from $10 \mathrm{kN}$, the authors found traverse force reductions of about $0.5 \mathrm{kN}$ per $100 \mathrm{rpm}$ attributed to the extended softening of the material. Nevertheless, with higher spindle speed the traverse force rose again suggesting an optimum for the tool rotation speed.

Another common option for lowering the process forces in FSW are adjustments changes to welding tools or even to tooling concepts. Since the shoulder has typically the highest impact on the process forces due to its geometrical dimensions, a common first approach is to reduce the shoulder diameter and by this the contact area of tool and workpiece. Mahoney et al. [11] showed early that FSW is possible with shoulder to pin diameter ratios of smaller than 1.5-1, which resulted in lower forces, steeper temperature gradients and a reduced thermal and mechanical load while simultaneously the weld strength was improved. In accordance with that, Arora et al. [2] reported a halving of the spindle torque when they halved the shoulder diameter even though the temperature in the joining zone subsequently decreased by almost $200 \mathrm{~K}$ which in turn
Fig. 2 Material deformation (A) in front of the tool path and void formation (B) behind the tool (grey) as a consequence of insufficient backing. Remaining unwelded joint line (C) as a consequence of geometrical boundaries caused by the tool's shoulder
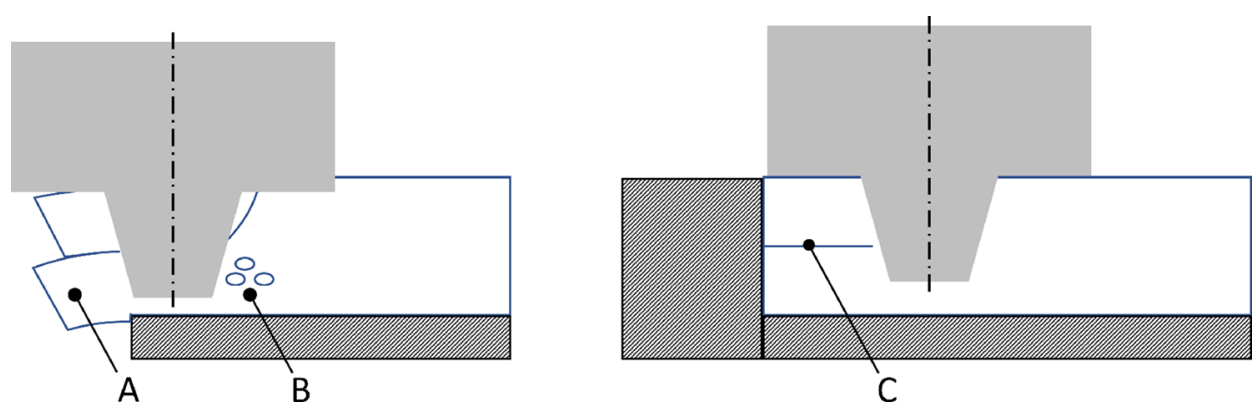
about doubled the flow stress of the welded material. Own work showed that the force and torque requirements for welding $20 \mathrm{~mm} \mathrm{Cu}-\mathrm{OF} / \mathrm{EN}-\mathrm{CW}$ 008A could be reduced significantly, e.g., from more than $100 \mathrm{kN}$ to $44 \mathrm{kN}$ normal force, by transferring several functions of the shoulder as compression to the pin and using a smaller tool with a shoulder to welding depth ratio of about 1 [4]. Geometrical alternations of the tool geometry such as adding flutes or flats usually result in a tradeoff between the different process forces. For example, by adding co-flow flutes to the pin the traverse force may be reduced by more than $25 \%$ while the normal force increases [13].

A different tooling concept of FSW that may be used to address the issues described above is Stationary Shoulder Friction Stir Welding (SSFSW) [15]. The concept of SSFSW consists of a rotating pin that protrudes through a hole in a non-rotation shoulder device. By this, the shoulder does not relevantly contribute to the heat input while the rotating pin provides a narrower and more concentrated linear heat input profile compared to the standard process. Consequently, the heat input as well as forces needed but also plastic part deformation can be reduced significantly. For example, $\mathrm{Wu}$ et al. [20] found a reduction of the heat input of about 30\% under optimum process conditions when comparing SSFSW to conventional FSW.

A further process concept that is capable of reducing energy input and in particular traverse forces during FSW was patented by the Edison Welding Institute (EWI) in 2004 [19]. This tooling concept usually referred to as Variable Penetration Tool (VPT) should also be discussed shortly since it uses the term "shoulderless" as well and has therefore to be distinguished from the own concept and its targets in the following. The central element of EWI's FSW concept is a monolithic pointed conical tool which is not fully submerged into the joint during welding, Fig. 3. The concept's main target is to address the issue of closure welding in FSW, furthermore it is well capable of variable thickness and open-loop control welding as has been reported by Lammlein et al. [10]. Moreover, the same authors found significant reductions of all process related forces comparing them with their standard reference FSW case, especially spindle torque (around 60\%) and traverse forces (around 80\%). However, with a typical opening angle between 70 and $160^{\circ}$ [19] contact area and so normal forces increase fast with increasing welding depth analogous to the standard FSW process, e. g. exactly quadratic for a $90^{\circ}$ opening angle as used by Lammlein et al. [10]. Accordingly, Zhang et al. report very similar normal force values compared to their standard FSW reference process when applying EWI's concept to $\mu \mathrm{FSW}$ [22].

An inherent issue of the tooling concept is that due to the introduction of the pointed cone as a "shoulderlike geometry" which is immanently needed for material compression and consolidation during welding it shares comparable geometrical limitations with standard FSW

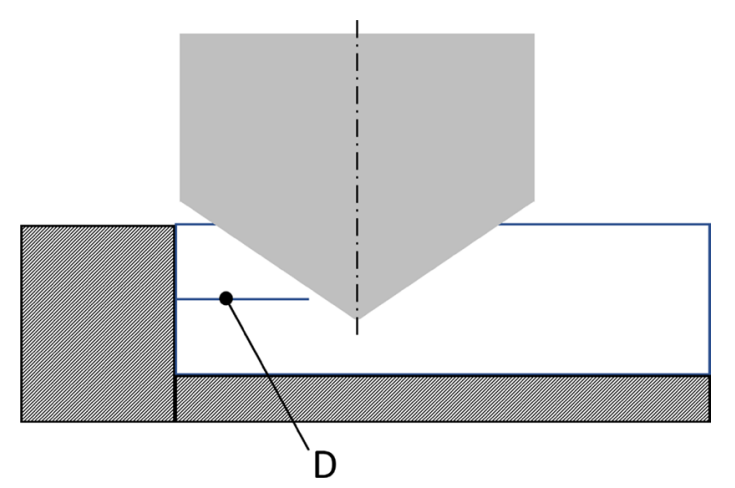

Fig. 3 EWI's "shoulderless" FSW approach with pointed conical probe and partial submersion. Remaining unwelded joint line (D) as a consequence of the geometrical characteristic of the tooling concept

processes using a shoulder and is so not able to join parts fully up to edges, cmp. Figure 3 . Moreover and with regard to the targets of this work, Lammlein et al. found that, compared to standard FSW, weld line following was more critical with a pointed conical geometry since the decreasing diameter near its tip leads to a reduced robustness of the process against line alignment errors of the tool [10].

While all those approaches can be used to improve the problem of high forces during FSW, none is able to solve it to its full extent. This stems mainly from the fact that all approaches described above still require high normal forces and still have geometrical limitations especially when joining components fully to edges. Central element of these remaining issues is the use of a tool shoulder (or shoulderlike geometrical elements respectively) in all concepts and approaches. The shoulder has the largest contact area and so contributes dominantly to normal and traverse forces. A larger shoulder diameter directly increases the effective lever and so the spindle torque needed for the process. By this, the shoulder generates a lot of heat but only at the top of the weld although it is needed homogeneously distributed over the welding depth for an efficient joining process. All these issues intensify with increasing welding depth. Taken together, these shortcomings have led to the development of Shoulderless Friction Stir Welding (SLFSW) with a focal point on deep welding of labile structures, the concept of which is described and validated in the next section.

\section{Shoulderless friction stir spot welding- concept, tool design, prerequisites, and features}

The concept of SLFSW uses several elements of the FS approaches described in the last section and in general simplifies the conventional FSW process by leaving the shoulder out. But since an approach of the tool almost fully 
up the components edge is needed for inducing the joining process here and so for fully joining parts, geometrical elements outside the actual joining zone had strictly to be avoided. Therefore and unlike other approaches like EWI's VPT concept or SSFSW, no shoulder or shoulder-like elements are used: the SLFSW tool is comparably slim with no or an only slightly conical shape, Fig. 4. Furthermore, if a conical shape is used, the diameter of the SLFSW tool at its top is derived from the projected actual joining zone at its bottom. This design allows the edge of the component to be reached by tool and process impact, in particular deeper in the joining zone, and contact area and thus process forces develop significantly differently than in the approaches presented in the last section: Once the tool is plunged, contact area in normal direction and so normal forces are comparatively little dependent on the welding depth for small conical angles. For the same reason, the total contact area of the tool and so torque requirements increase rather linearly than quadratically with increasing penetration depth.

While this geometrical design directly improves all shoulder related issues described, SLFSW is still based on the very same principles of the conventional FSW process. Therefore FSW's main process phenomena, i.e., heat balance and especially the consolidating material flow, have to be sufficiently established and ensured without the shoulder to produce a defect free weld. For ensuring this, several important main functions of the original tool shoulder such as heat input, material flow, containment and compression during the welding process and especially during deposition have to be transferred to the pin and subsequently considered in the welding process execution.

\subsection{Transfer of shoulder functions and tool design}

The resulting tool design based on those requirements is shown in Fig. 5. With $20 \mathrm{~mm}$ length and a diameter

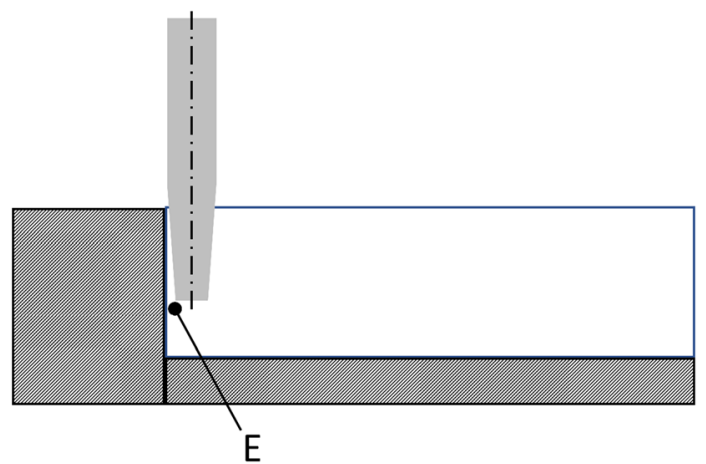

Fig. 4 Concept idea of SLFSW with slim tooling and an approach almost to the edge of the component. Fully welded joint line (E) realized by a short distance from tool contour to edge and a strong material flow induced by active material flow structures of the tool

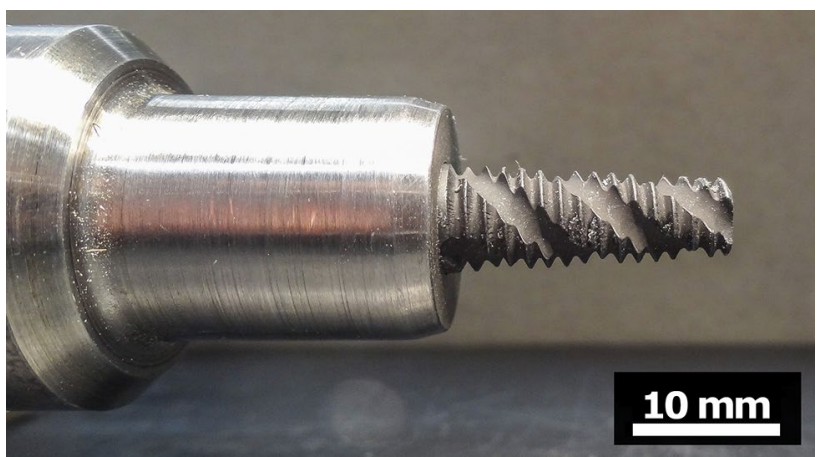

Fig. 5 Details of tool design: tool from the side with mount (silver) and perspective from below

of $8 \mathrm{~mm}$ at the top and $6 \mathrm{~mm}$ at the bottom the tool is small and slim and so minimizes lever and contact area. This results in comparatively low torque and normal force requirements and improves the plunging speed. Due to its slightly conical shape, the tool partially covers the actual joining zone below during processing. This prevents an oxidation of the material there, provides compression and improves the material feed to the joining zone especially during traversing.

The outer contour of the tool features three deep spiral grooves with superimposed threads. The tool's spiral grooves result in a tool volume to rotation volume fraction of $60 \%$. Therefore, a material volume of about $475 \mathrm{~mm}^{3}$ can be actively stirred and transported inside the tool volume with each revolution. Similar to the working principle of a worm pump, the material is so transported to and compressed at the lower end of the pin. This "pump effect" increases the pressure in the joining zone, compresses material during deposition and simultaneously hinders material from exiting at its top. By this, the corresponding shoulder functions in standard FSW are directly replaced. Moreover, the spiral grooves fulfill further functions: During traversing, they facilitate the material flow from the front to the back of the tool by providing a passage through the tool. This reduces the pressure in front of the tool and thus the traverse force, cmp. [5]. In addition, the material volume carried along in the spirals can be used as a buffer to compensate for small disturbances in the process and material flow.

The superimposed threads on the tool support the consolidation of the material flow and therefore have a smaller pitch than the spirals. Their sharp edges induce a high shearing of the material which improves the flowability of the material, extends the joining zone several millimeters beyond the tool and provides a better joining with the surrounding base material. Furthermore, they also improve wear behavior and so tool life, cmp. [11]. The tools used for this study were 
made from $\mathrm{QRO}^{\circledR} 90$ hot-working tool steel, hardened and annealed to $45 \mathrm{HRC}$.

\subsection{Features and Details of SLFSW illustrated based on Linear Welds}

Initially, the SLFSW technique was developed to replace rivets and bolts. Nevertheless, linear welds are possible as well and are even more suitable to investigate certain process characteristics like the material flow or the resulting microstructure more isolated and in detail. Figure 6 shows the outer surface and the cross-section of a linear weld in AA 6061-T651 with $6.5 \mathrm{~mm}$ penetration depth of the tool, a spindle speed of $1200 \mathrm{rpm}$ and a traverse speed of $100 \mathrm{~mm} /$ min. The parameter set resulted in an average normal force of less than $3000 \mathrm{~N}$ during traversing and an average spindle power of $1005 \mathrm{~W}$, which is about $15-20 \%$ and about $20-25 \%$ respectively of a conventional FS weld with shoulder at the same welding depth. With an energy per unit length of about $600 \mathrm{~J} / \mathrm{mm}$ the energy needed for joining is already reduced by about two thirds. Furthermore, a normal force of less than $3500 \mathrm{~N}$ could be maintained during plunging with $20 \mathrm{~mm} /$ $\min$.

While the outer surface roughness is obviously very high compared to other FSW variants, it can be seen from the cross-section that this roughness is limited to the very top of the weld, i.e., to a maximum of $0.75 \mathrm{~mm}$ with an overall material loss from the joining zone of about $5 \%$. The remaining weld is found well consolidated and shows no voids or other weld defects. Two of three characteristic material flow regimes of standard FSW processes can be identified in the cross-section for SLFSW as well: a flow regime that contributes especially to the vertical intermixing of the material and reaches from the top of the weld to a flow regime at the bottom where the intermixing is primarily horizontal. Obviously, the flow regime usually caused by the shoulder in standard FSW does not exist in SLFSW. In both pin flow regimes found, the high shearing of the material induced by the tool combined with the heat input of the process results in the formation of a fine grain that can be attributed to continuous dynamic recrystallization (CDRX), cmp. [8]. This can be seen in particular in the lower pin flow regime at the bottom, where the pump effect of the tool results even in the formation of a partially separated material flow disc with a clearly distinguishable microstructure. Furthermore, except for a flash formation on the advancing side, the pump effect effectively avoids a significant material loss out of the joining zone. The joining zone in turn is well bonded to the surrounding base material which shows no visible thermal or mechanical impact like grain distortions or (dynamic) recrystallization. This results in a sharp microstructural transition while in contrast to

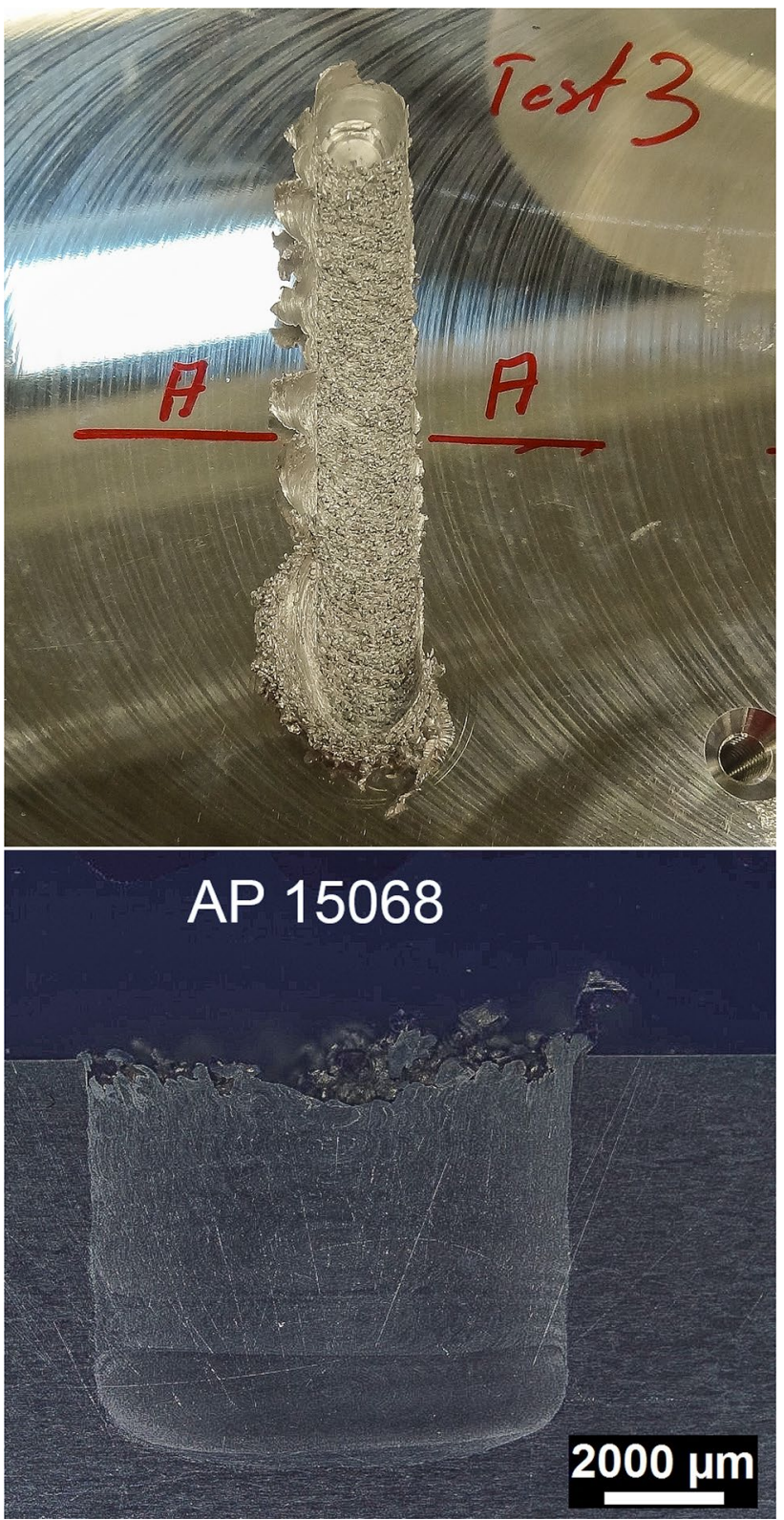

Fig. 6 SLFSW: Outer appearance and cross-section of a linear weld with a spindle speed of $1200 \mathrm{~min}^{-1}$, a tool penetration depth of $6.5 \mathrm{~mm}$ and a traverse speed of $100 \mathrm{~mm} / \mathrm{min}$

conventional FS-welds no blurry transition is found on the retreating side of the weld. As a whole, the joining zone is $7.95 \mathrm{~mm}$ wide at the lower pin regime with a maximum welding depth of $6.90 \mathrm{~mm}$. This is remarkable considering a pin width of $6 \mathrm{~mm}$ at the bottom and a plunging depth of the tool of $6.50 \mathrm{~mm}$ and underlines the intensive but locally limited process impact caused by SLFSW. Taken together, it can be stated that the process impact of SLFSW is limited to a small area directly around the joint line. Furthermore, in comparison to standard FSW the heat input is distributed more homogeneously over the entire welding depth and a 
smaller volume of material is deformed for realizing the same welding depth.

\subsection{Influence of spindle speed on microstructure}

Fig.7a shows the cross-section of a weld with a spindle speed of $2000 \mathrm{rpm}$ and otherwise the same process parameters. With increasing spindle speed and so heat input, the pump effect of the tool also increases, circulates more material, and increases the (dynamic) pressure in the lower pin regime. By this, the material flow in the lower material flow regime of the pin separates more and more. This phenomenon is comparable to the known effect of "over-stirring"

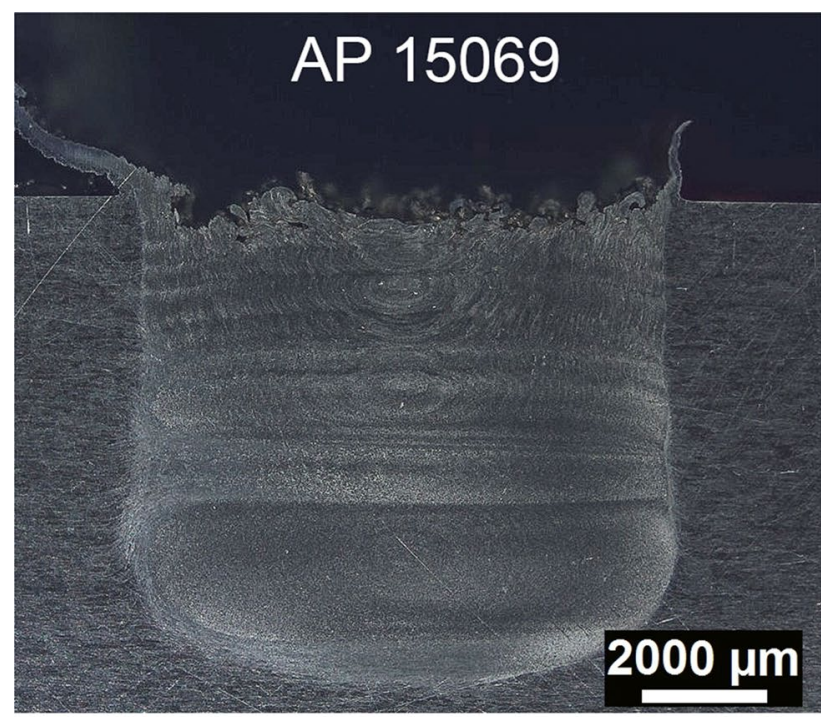

(a) $2000 \mathrm{~min}^{-1}$

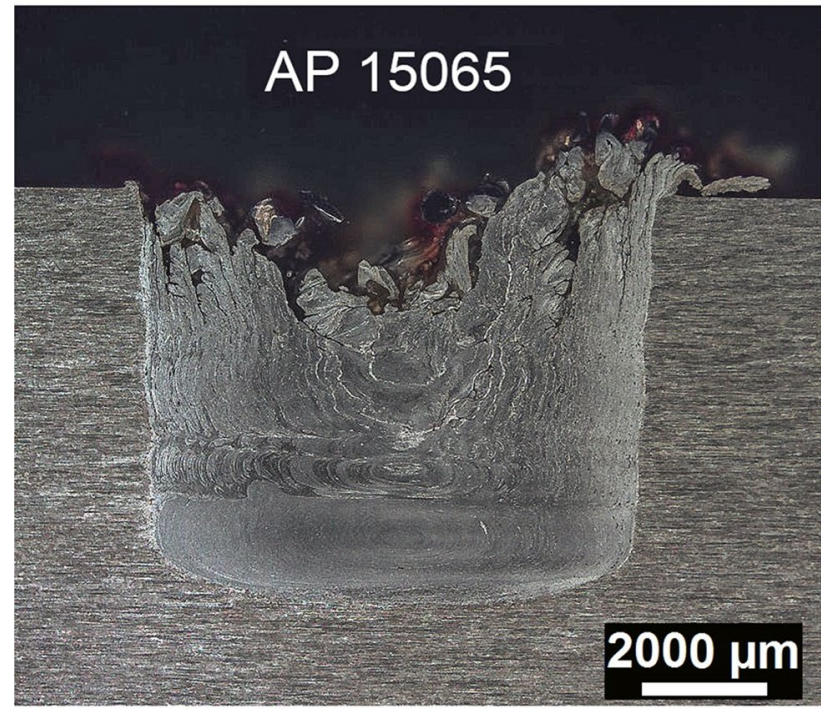

(b) $700 \mathrm{~min}^{-1}$

Fig. 7 Cross-sections of the linear welds performed with different spindle speeds but also with $100 \mathrm{~mm} / \mathrm{min}$ traverse speed and $6.5 \mathrm{~mm}$ plunging depth of the tool in conventional FS welds and further intensifies the disc formation. This separation of the material flow in the lower pin regime hinders vertical mixing, which results in an increase in horizontal mixing in adjacent areas above. As a consequence, a beginning formation of horizontal material flow patterns similar to the material flow disc can be found here. Along with this, the process impact is significantly extended with an increased welding depth of $7.85 \mathrm{~mm}$ and a widened welding zone of even $8.75 \mathrm{~mm}$ at the bottom. The welding zone here is even wider than at the surface with a microstructure that now shows a FSW typical more blurry transition to the surrounding base material on the retreating side (left) that can be attributed to the higher heat input. Since the increased heat input causes an extended softening of the material, the normal force is reduced by about $750 \mathrm{~N}$ to $2250 \mathrm{~N}$ compared with the spindle speed level of $1200 \mathrm{rpm}$. Because of the higher pump effect, the material loss from the joining zone is reduced to about $3 \%$ while from the microstructure an active material flow can be identified even at the very top of the weld.

In contrast to that, a decreased spindle speed results in the opposite as can be seen from the cross-section of a weld performed with $700 \mathrm{rpm}$, Fig. 7b. With the reduced pump effect of the tool, the material is not sufficiently contained, stirred, and heated. This results in a material loss to the surface and furthermore an insufficient bonding of the weld to the surrounding base material. From the cross-section a material loss ratio from the joining zone of about $12 \%$ can be determined with surface cavities that are up to $2.25 \mathrm{~mm}$ deep. Only the material flow at the bottom of the pin remains intact with a fully dynamically recrystallized microstructure. The remaining material flow is found very unstable especially in the center of the weld and close to free surfaces or regions with material loss respectively. On both sides of the weld, the material is better supported by the surround base material which enables a limited material flow especially on the advancing side (right). Here, the weld is better bonded to the base material an shows a more homogeneous transition compared to the retreating side (left).

As a consequence, the microstructure generally shows typical signs of an insufficient heat input, material flow or shearing: Oxides are not mechanically broken up and dispersed in the weld with the different material flow layers of the FS process being not consolidated. Accordingly, the size of the joining zone is reduced to a width of below $7.50 \mathrm{~mm}$ and a welding depth of $6.60 \mathrm{~mm}$.

\subsection{Sensitivity analysis of process forces}

In the last sections it has been shown that SLFSW may significantly reduce the process forces compared to a standard 
FSW process. Furthermore, the tooling concept of SLFSW results in a characteristic dependence of process forces and required spindle torque from the main process parameters. Table 1 gives an overview of this development and additionally as calculated results also of power and heat input per unit length with increasing traverse speed for two spindle speed levels.

It can be recognized from the representation that increasing the spindle speed by $66.7 \%$ from 1200 to $2000 \mathrm{rpm}$ results in a direct decrease in normal force and spindle torque. Ranging between 28.8 and $30.6 \%$ for normal forces and between 30.7 and $32.3 \%$ for spindle torques those reductions are found to be very similar and consistent for all investigated traverse speed levels. Analogous with this comparatively linear change in torque and thus spindle power, a linear dependence results for the heat input per unit length as well which is about $14 \%(13.1-15.5 \%)$ higher for all respective traverse speeds of the $2000 \mathrm{rpm}$ level.

While both spindle speed levels show steady increases in normal force and required spindle power with increasing traverse speed, these increases remain comparatively moderate: For the $1200 \mathrm{rpm}$ level, doubling the traverse speed from 100 to $200 \mathrm{~mm} / \mathrm{min}$ results in an increase of only $5.8 \%$ in normal force and $4.5 \%$ in spindle torque, which consequently reduces the heat input per unit length by $47.8 \%$ to $314 \mathrm{~J} / \mathrm{mm}$. For the $2000 \mathrm{rpm}$ level, these increases are even smaller: $3.0 \%$ in normal force and $2.7 \%$ in spindle torque for the same increase in traverse speed, reducing the heat input per unit length by $48.6 \%$.

Within both spindle speed levels the reduction of the heat input per unit length develops non-linearly with increasing traverse speed: $32.4 \%$ from 100 to $150 \mathrm{~mm} / \mathrm{min}, 22.9 \%$ from 150 to $200 \mathrm{~mm} / \mathrm{min}$ and $19.4 \%$ from 200 to $250 \mathrm{~mm} / \mathrm{min}$ for $1200 \mathrm{rpm}$, and $32.0 \% / 24.5 \%$ / 19.2\% for $2000 \mathrm{rpm}$ respectively. Thus, this development with traverse speed shows an asymptotic, self-stabilizing pattern. Furthermore, the heat input per unit length for both speed levels converges with increasing traverse speed with differences of $89 \mathrm{~J} / \mathrm{mm}$ for $100 \mathrm{~mm} / \mathrm{min}, 63 \mathrm{~J} / \mathrm{mm}$ for $150 \mathrm{~mm} / \mathrm{min}, 41 \mathrm{~J} / \mathrm{mm}$ for $200 \mathrm{~mm} / \mathrm{min}$, and $34 \mathrm{~J} / \mathrm{mm}$ for $250 \mathrm{~mm} / \mathrm{min}$. Both effects are characteristical for FSW processes [5, 21].

\section{Industrial use case-implementation of SLFSW and discussion}

The industrial use case presented in the following is a vacuum gate valve consisting of a lever and a plate which were originally connected by screws, Fig. 8 . Vacuum gate valves are used in particular to separate processing chambers and/ or transfer passages in manufacturing of integrated circuits and semiconductors. Since those components as well as the respective production processes are highly sensitive, handling, processing, and transport have to take place carefully in a protected (vacuum) environment to avoid negative influences, especially contamination with process-damaging micro particles. Besides contamination caused by

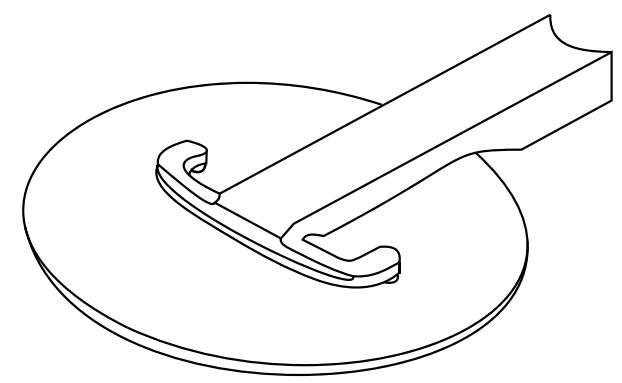

Fig. 8 Overview of vacuum gate valve in its final configuration and connected by SLFSW
Table 1 Sensitivity analysis: Influence of main process parameters on process forces and heat input

\begin{tabular}{|c|c|c|c|c|c|}
\hline Spindle speed & {$[\mathrm{mm} / \mathrm{min}]$} & Normal force $^{a}$ & Spindle torque ${ }^{a}$ & Power & $\begin{array}{l}\text { Heat input } \\
\text { per unit } \\
\text { length } \\
{[\mathrm{J} / \mathrm{mm}]}\end{array}$ \\
\hline $1200^{b}$ & 100 & 2993 & 7.98 & 1003 & 602 \\
\hline 1200 & 150 & 3084 & 8.10 & 1018 & 407 \\
\hline 1200 & 200 & 3166 & 8.34 & 1048 & 314 \\
\hline 1200 & 250 & 3189 & 8.40 & 1056 & 253 \\
\hline $2000^{c}$ & 100 & 2132 & 5.50 & 1152 & 691 \\
\hline 2000 & 150 & 2192 & 5.61 & 1175 & 470 \\
\hline 2000 & 200 & 2197 & 5.65 & 1183 & 355 \\
\hline 2000 & 250 & 2242 & 5.71 & 1196 & 287 \\
\hline
\end{tabular}

\footnotetext{
${ }^{a}$ Average during steady state of the respective SLFSW process. At least 100 consecutive values at $10 \mathrm{~Hz}$.

${ }^{\text {b}}$ Outer appearance and cross-section shown in Fig. 6.

${ }^{\mathrm{c}}$ Cross-section shown in Fig.7a
} 
external sources, inner particle generation in those systems has become an increasingly important issue during the last decade. Inner particle generation stems primarily from the actuation of mechanical components such as said valves and is typically a result of friction and abrasion, mostly metal to metal contact. In this context, especially screw connections inside vacuum regions are critical and additionally harbor the risk of so-called virtual inner vacuum leakage. When the valve interior is evacuated, certain parts of the screw threads are closed in a more or less gas-tight manner from the remaining surroundings. During and after evacuation, the remaining gas then escapes slowly and contaminates the interior, e.g., of the processing chamber.

Consequently, the SLFSW implementation shown in the following addresses those issues and substitutes the original screw connection between lever and plate. Further details about the screw variant of the component can be found in the related published patent, cf. [3]. As can be seen from Fig. 9, an almost direct and space-neutral implementation of the technology is possible with only minor changes to the original part design. In order to fully substantially improve the situation, it is essential that both parts are fully joined without remaining or newly generated gaps. Of course, all basic requirements of the old design have at least to be met such as the original mechanical behavior of the component, e.g., stiffness or static and fatigue strength. The parts are joined by SLFSW using a sweep technique which increases the load-bearing cross-section of the component while keeping the tool access area and the respective forces during processing small. The corresponding procedure is comparable to ISO 18785 and shown schematically in Fig. 10.

Since subsequent machining of the component is neither desirable for economic reasons nor the needed accessibility is in general technologically given afterwards, both parts already have their final outer geometry at the time of welding. After welding, only the joining zone is milled directly in the same fixture with a PCD (polycrystalline diamond) form cutter which is overall already the final machining operation. Since all connections of the component are already machined at the time of joining, the welding process has to reach a very high geometrical precision (typically $+/-0.05 \mathrm{~mm}$ ). Due to this, even the smallest outer plastic
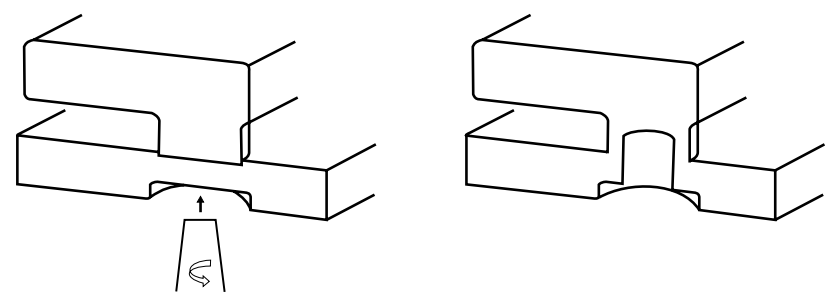

Fig. 9 Schematic part configuration with joint position before welding and after subsequent milling (a)

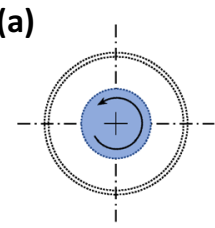

1) plunging

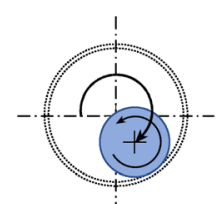

4) perform

(b)
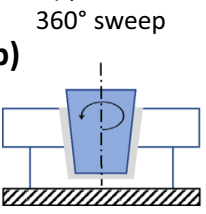

1) plunging

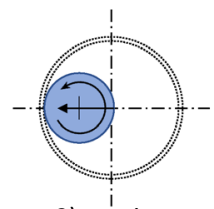

2) moving

outwards

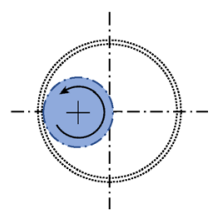

5) stop sweep

motion

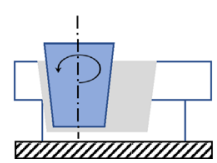

2) moving outwards

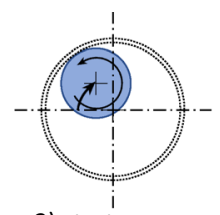

3) start sweep

motion

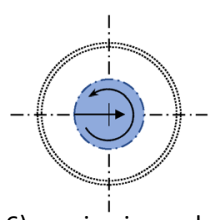

6) moving inwards \& retraction

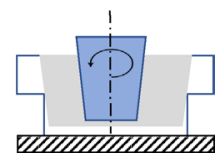

6) moving inwards \& retraction

Fig. 10 Schematic representation of the welding procedure used with tool (blue). a Top view $\mathbf{b}$ side view with process impact/welded area (grey). Illustration based on [17]

deformation of the component has to be avoided during welding. In addition, any kind of damage to surfaces such as smallest scratches or dents for example caused by burrs are not allowed with regard to the target application of the component.

One approach for supporting this is the anticipation of the process-immanent keyhole with a profile cutter before welding, cmp. Fig. 9. This significantly reduces the duration of heat input during plunging and thus heat flow into and heating of adjacent areas around the joining zone. The surrounding component so not only deforms less but also supports the joining zone better from the sides. Furthermore, weld cycle time and spindle load duration are improved a lot while the three-dimensional contact during contact initiation reduces vibrations and bending moments on the comparatively long and thin tool. With these prerequisites, the fully automated cycle with tool change and approach, welding the two parts with a joining area of about $135 \mathrm{~mm}^{2}$ in a sweep technique and tool retraction becomes possible in less than 10 seconds. Moreover, no extensive lower or lateral support of the joining partners or the joining zone is needed although the tool approaches the edge of the component to some tenths of a millimeter, cmp. Fig. 10. The parameters of the SLFSW process regarded in the following are a spindle speed of $2000 \mathrm{rpm}$ and a traverse speed of $300 \mathrm{~mm} / \mathrm{min}$ resulting in a heat input of not more than $850 \mathrm{~W}$ or an energy per unit length of around $170 \mathrm{~J} / \mathrm{mm}$.

Figure 11 shows a cross-section of the welding result after subsequent milling. The welding zone (center) is 
very homogeneous, fully consolidated and free of welding defects, i.e., voids. As being characteristically for all FS processes, the whole weld is fully dynamically recrystallized (CDRX) and can therefore clearly be distinguished from the surrounding base material visually, both for upper and lower part. CDRX results in a very fine uniaxial grain of about $5-10 \mu \mathrm{m}$ in the pin regime while the grain size is even too fine to be determined by light microscopy at the lower pin profile (disc) what leads to an estimated grain size of below $1.5 \mu \mathrm{m}$. Based on tool path and the asynchronous material deposition respectively, material flow patterns closely related to the well-known onion rings of standard FSW processes can be recognized in the whole cross-section.

Although the very extensive dynamic recrystallization of the weld indicates a considerable process impact from heat input and material flow within the joining zone, the very low overall heat results in a very small process impact beyond. As a direct result, the thermo-mechanically affected zone (TMAZ) is consistently about $50 \mu \mathrm{m}$ wide or less, while no heat affected zone (HAZ) can be identified, see Detail A in Fig. 11. In turn, compared to conventional FS welding a hardness drop of about 45 HV 1 is avoided here. Process impact and tool trajectory are yet suitable to completely dissolve the original joint line while no joint line remnants (JLRs) can be recognized in the cross-section. While the plastic deformation induced by the process pushes material here slightly to the sides resulting in a desired small fillet between the two parts, no remaining gaps or cracks can be found. The weld is directly well machinable what results in clean surfaces after milling with the possibility of machining to mirror-finish. The resulting geometry of the component provides an improved flow of forces compared to the screw variant and a more homogeneous and better component behavior especially against alternating loads and bending moments. Several inner stress concentrators such as the stiffness mismatch between screw and component material are eliminated as well. No sources of inner particle generation exist anymore with the new solution while only outer surfaces remain which are all visually good to check and easy to clean. During life testing, the component achieved more than three times the life of the screw variant without any failure, particle generation or detectable crack initiation.

\section{Conclusions}

In this study, the concept of Shoulderless Friction Stir Welding (SLFSW) was presented. For leaving the shoulder out, the central functions of the shoulder, i.e., heat input, material flow, containment and compression during the welding process and during deposition, had to be transferred to the pin and subsequently considered in the welding process execution.

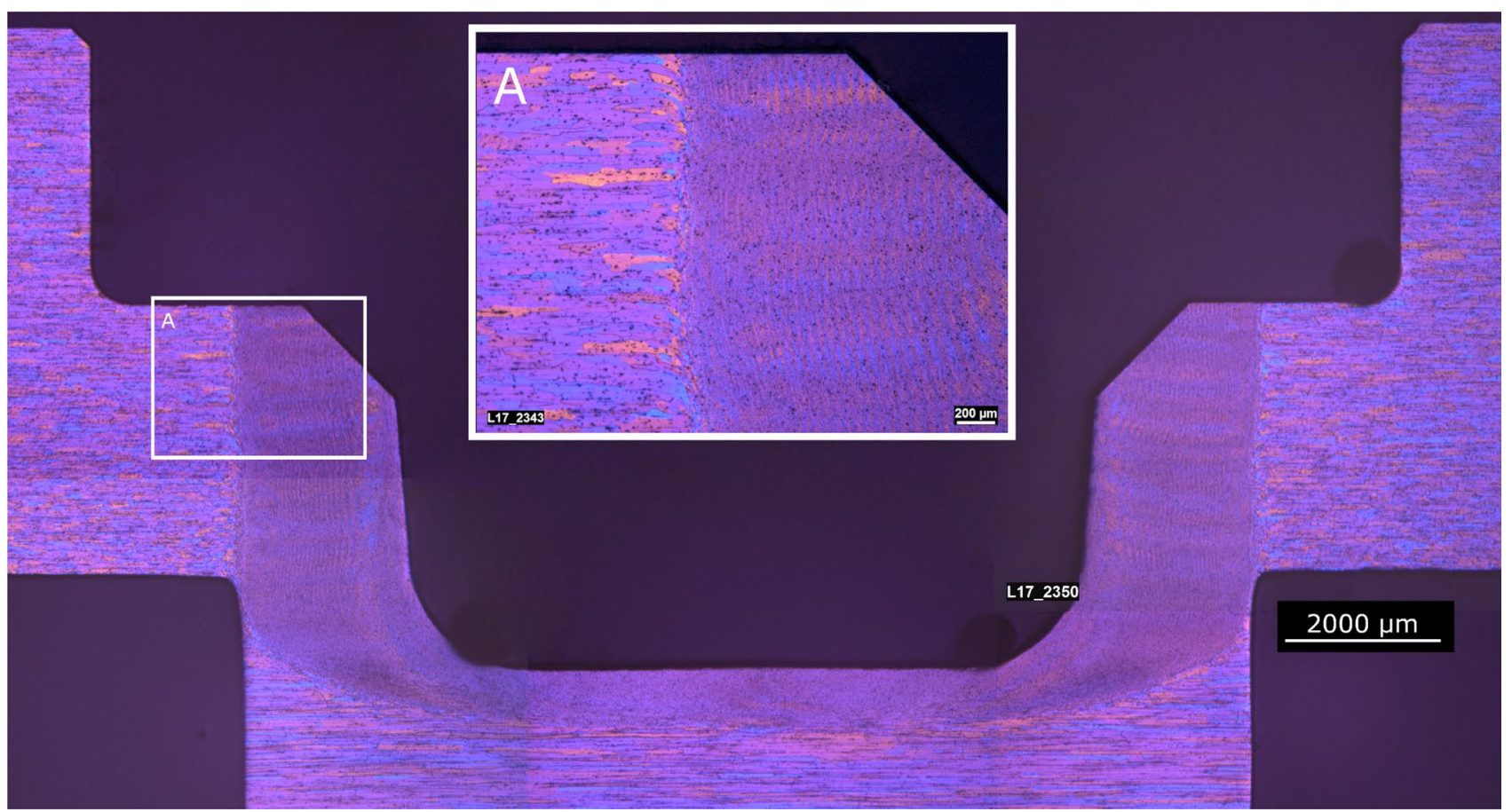

Fig. 11 Cross-section of the welding result after subsequent milling with detail of milled surface material flow patterns and transition from weld to base material 
The resulting tool design of SLFSW is small and slim and so reduces contact area, effective lever and directly allows for weld paths almost at the edge of components. The design presented is highly contoured with three deep spiral grooves with superimposed threads resulting in a high tool volume to rotation volume fraction of $60 \%$ initiating an effect comparable to a worm pump. As shown on the basis of linear welds with $6.5 \mathrm{~mm}$ tool penetration depth in AA 6061-T651, SLFSW is capable of producing defect free welds with a very high process efficiency. Nevertheless, the process principle of SLFSW causes a high surface roughness of some tenths of a millimeter on top of the weld which have to be removed for most use cases, e.g., by milling. With an average normal force of less than $3000 \mathrm{~N}$ and an average spindle power of about $1 \mathrm{~kW}$, force reductions of $80-85 \%$ and power reductions of $75-80 \%$ were found compared to a standard FSW process. Furthermore, the energy per unit length needed for welding was reduced by more than two thirds. In contrast to standard FSW, the process impact in SLFSW can be limited to a very small area directly around the joint line while the heat input is distributed homogeneously over the entire welding depth. Accordingly, the microstructure shows a very sharp transition to the surrounding base material while all microstructural main features of FS processes such as a very fine and fully dynamically recrystallized uniaxial grain can be found.

For demonstrating the practical suitability of the new joining technology, an industrial application from vacuum technology was presented, taking advantage of SLFSW's capability of joining labile components fully to edges. Screw connections of a vacuum gate valve were replaced using a sweep technique, removing sources of inner particle generation and so-called virtual inner vacuum leakage. With an energy per unit length of only around $170 \mathrm{~J} / \mathrm{mm}$ no extensive lower or lateral support of the joining zone is needed and a part precision of typically $+/-0.05 \mathrm{~mm}$ could be reached. Based on these results, further potential for SLFSW with regard to reduction of forces, distortion and residual stresses can be identified. In addition, the results presented open up great potential for integration of SLFSW with other spindle processes like milling.

Acknowledgements The author wants to thank in the first place VAT Vakuumventile AG, Switzerland, for the permission to publish the application related to this research. Rapid Technic AG, Switzerland, has supported this publication with a vast amount of additional material from its extensive FSW database and substantial in-kind contributions. Rudi Scheck from the MPA Stuttgart has prepared the barker etched cross section with his indisputable unique skills. Volkher Onuseit has supported this publication significantly by discussion, sheer wisdom, and coffee.

Funding Open Access funding enabled and organized by Projekt DEAL. This research received no external funding.
Availability of data and materials Further data such as micro-sections or machine logs is available from the author upon request.

Code availability Not applicable.

\section{Declarations}

Conflict of interest The author declares no conflict of interest.

Open Access This article is licensed under a Creative Commons Attribution 4.0 International License, which permits use, sharing, adaptation, distribution and reproduction in any medium or format, as long as you give appropriate credit to the original author(s) and the source, provide a link to the Creative Commons licence, and indicate if changes were made. The images or other third party material in this article are included in the article's Creative Commons licence, unless indicated otherwise in a credit line to the material. If material is not included in the article's Creative Commons licence and your intended use is not permitted by statutory regulation or exceeds the permitted use, you will need to obtain permission directly from the copyright holder. To view a copy of this licence, visit http://creativecommons.org/licenses/by/4.0/.

\section{References}

1. Arbegast WJ (2008) A flow-partitioned deformation zone model for defect formation during friction stir welding. Scripta Mater 58(5):372-376. https://doi.org/10.1016/j.scriptamat.2007.10.031

2. Arora A, De A, Debroy T (2011) Toward optimum friction stir welding tool shoulder diameter. Scripta Mater 64(1):9-12. https:// doi.org/10.1016/j.scriptamat.2010.08.052

3. Blecha T, Gfeller R, Hoßfeld M (2015) Closure element for a vacuum seal having a friction stir welding connection

4. Hossfeld M (2015) High speed friction stir welding of thick copper plates. Fourth International Conference on Friction Stir Welding and Processing (FSWP'2015) . https://doi.org/10.18419/ OPUS-8826

5. Hoßfeld M (2016) Experimental, analytical and numerical investigations of the friction stir welding process. Universität Stuttgart . https://doi.org/10.18419/OPUS-8957

6. Hossfeld M (2019) Time-dependency of mechanical properties and component behavior after friction stir welding. Int $\mathbf{J} \mathrm{Adv}$ Manuf Technol 102(5-8):2297-2305. https://doi.org/10.1007/ S00170-019-03324-X

7. Hossfeld M, Hofferbert D (2018) Challenges and state of the art in industrial fsw - pushing the limits by high speed welding of complex 3d contours. 12th International Symposium on Friction Stir Welding. https://doi.org/10.18419/OPUS-9952

8. Jata KV, Semiatin SL (2000) Continuous dynamic recrystallization during friction stir welding of high strength aluminum alloys. Scripta Mater 43(8):743-749. https://doi.org/10.1016/S13596462(00)00480-2

9. Kalidass S, Gnanasekaran S, Akilesh AR, Gokul Kumar NT, Aswin M, Rajendran C, Sonar T (2021) Investigation of shoulder diameter to sheet thickness $(\mathrm{d} / \mathrm{t})$ ratio on tensile properties friction stir welded aa2014-t6 aluminum alloy joints. Advances in Materials and Processing Technologies pp. 1-14 . https://doi.org/ 10.1080/2374068X.2021.1970988

10. Lammlein DH, DeLapp DR, Fleming PA, Strauss AM, Cook GE (2009) The application of shoulderless conical tools in friction stir welding: an experimental and theoretical study. Materials Design 30(10):4012-4022. https://doi.org/10.1016/j.matdes.2009.05.023 
11. Mahoney M (2018). Learning from the past. 12th International Friction Stir Welding Symposium, Chicoutimi, Quebec

12. Mishra RS, De PS, Kumar K (2014) Friction Stir Welding and Processing. Springer International Publishing, Cham. https://doi. org/10.1007/978-3-319-07043-8

13. Reza-E-Rabby M, Tang W, Reynolds A (2016) Effect of tool pin features and geometries on quality of weld during friction stir welding. In: Mishra R, Mahoney MW, Sato Y, Hovanski Y, Verma $\mathrm{R}$ (eds) Friction Stir Welding and Processing VII. Springer International Publishing, Cham, pp 163-171. https://doi.org/10.1007/ 978-3-319-48108-1_17

14. Russell, MJ (2004) Development of improved tool designs and parameters for the friction stir butt welding of $1.2,6$ and $25 \mathrm{~mm}$ thickness aluminium alloys: Document no. 13201.01/03/1183.3. TWI Members Report 801/2004, 1-44

15. Russell MJ, Blignault C, Horrex NL, Wiesner CS (2008) Recent developments in the friction stir welding of titanium alloys. Welding World 52(9-10):12-15. https://doi.org/10.1007/BF03266662

16. Shrivastava A, Krones M, Pfefferkorn FE (2015) Comparison of energy consumption and environmental impact of friction stir welding and gas metal arc welding for aluminum. CIRP J Manuf Sci Technol 9:159-168. https://doi.org/10.1016/j.cirpj.2014.10. 001
17. Su ZM, He RY, Lin PC, Dong K (2014) Fatigue analyses for swept friction stir spot welds in lap-shear specimens of alclad 2024-t3 aluminum sheets. Int J Fatigue 61:129-140. https://doi.org/10. 1016/j.jifatigue.2013.11.021

18. Thomas W, Nicholas E, Needham J, Murch M, Temple-Smith P, Dawes C (1991) Improvements relating to friction welding

19. Trapp TJ, Fisher JJJ, Bemath JJ (2004) Retractable shoulderless variable penetration friction stir welding tool

20. Wu H, Chen YC, Strong D, Prangnell P (2015) Stationary shoulder fsw for joining high strength aluminum alloys. J Mater Process Technol 221:187-196. https://doi.org/10.1016/j.jmatprotec.2015. 02.015

21. Yi D, Onuma T, Mironov S, Sato YS, Kokawa H (2017) Evaluation of heat input during friction stir welding of aluminium alloys. Sci Technol Welding Joining 22(1):41-46. https://doi.org/10. 1080/13621718.2016.1183079

22. Zhang C, Wang W, Jin X, Rong C, Qin Z (2019) A study on microstructure and mechanical properties of micro friction stir welded ultra-thin al-1060 sheets by the shoulderless tool. Metals 9(5):507. https://doi.org/10.3390/met9050507 